\title{
Stability and transport of titanium dioxide nanoparticles in three variable-charge soils
}

\author{
Ruichang Zhang ${ }^{1,2} \cdot$ Chen Tu ${ }^{3} \cdot$ Haibo Zhang ${ }^{4} \cdot$ Yongming Luo ${ }^{2,3,5}$ \\ Received: 17 July 2019 / Accepted: 26 October 2019 /Published online: 25 November 2019 \\ (C) Springer-Verlag GmbH Germany, part of Springer Nature 2019
}

\begin{abstract}
Purpose The exposure pathways and environmental impacts of titanium dioxide nanoparticles $\left(\mathrm{TiO}_{2} \mathrm{NPs}\right)$ released into soils could be significantly influenced by their stability and transport behaviors. The aim of this study was to investigate the stability and transport of $\mathrm{TiO}_{2} \mathrm{NPs}$ in three variable-charge soils and to determine the key factors controlling these behaviors.

Materials and methods Three surface $(0 \sim 15 \mathrm{~cm})$ variable-charge soils derived from quaternary red clay, humid ferralsols and stagnic anthrosols collected from Yingtan, Jiangxi Province (YT-H and YT-S, respectively), and humid ferralsols collected from Fuyang, Zhejiang Province (FY-H), were used in this study. Batch sedimentation experiments of $\mathrm{TiO}_{2} \mathrm{NPs}$ in soil suspensions were performed for $10 \mathrm{~h}$ to quantify their stability. Transport of $\mathrm{TiO}_{2} \mathrm{NPs}$ in soil columns was conducted with and without the presence of fulvic acid (FA).

Results and discussion Apart from soil organic matter (SOM) and iron oxides, there was no significant difference between the tested soils. Batch experiments showed that $\mathrm{TiO}_{2} \mathrm{NPs}$ were more stable in the YT-S soil suspension with high dissolved organic matter than in the YT-H and FY-H soil suspensions. In the column experiments, all $\mathrm{TiO}_{2}$ NPs were retained in YT-H and YT-S, while $11 \%$ of the $\mathrm{TiO}_{2} \mathrm{NPs}$ were eluted from $\mathrm{FY}-\mathrm{H}$ with a low amorphous iron oxide content. The significant retention of $\mathrm{TiO}_{2}$ NPs in the soils could be attributed to the straining and adsorption of $\mathrm{TiO}_{2} \mathrm{NPs}_{\mathrm{s}}$ on the surface of soil particles. FA enhanced the transport of $\mathrm{TiO}_{2} \mathrm{NPs}$ in YT-H and FY-H by dispersing the $\mathrm{TiO}_{2}$ NPs and reducing their adsorption onto soil particles, while all the $\mathrm{TiO}_{2}$ NPs dispersed in the FA solution were still deposited in YT-S with a high amorphous iron oxide content.

Conclusions The stability of $\mathrm{TiO}_{2} \mathrm{NPs}$ in three variable-charge soil suspensions was dependent on the SOM. However, the mobility of $\mathrm{TiO}_{2} \mathrm{NPs}$ in soils was not directly related to their stability in the soil suspensions. The difference in amorphous iron oxide content could induce the disparity in mobility of $\mathrm{TiO}_{2} \mathrm{NPs}$ in soils.
\end{abstract}

Keywords Amorphous iron oxide $\cdot$ Retention $\cdot$ Stability $\cdot$ Titanium dioxide nanoparticles $\cdot$ Transport $\cdot$ Variable-charge soil

\section{Introduction}

Titanium dioxide nanoparticles $\left(\mathrm{TiO}_{2} \mathrm{NPs}\right)$, one of the most widely used engineered nanomaterials in industry and daily

Responsible editor: Kitae Baek

\section{Yongming Luo}

ymluo@ issas.ac.cn

1 Chemical Engineering and Pharmaceutics School, Henan University of Science and Technology, 471023 Luoyang, People's Republic of China

2 Key Laboratory of Soil Environment and Pollution Remediation, Institute of Soil Sciences, 210008 Nanjing, People's Republic of China life, are inevitably released into the natural environment. Exposure modeling suggested that engineered nanoparticle concentrations in soil were higher than those in water and air, implying that soil might be a major sink for nanoparticles

3 Key Laboratory of Coastal Environmental Processes and Ecological Remediation, Yantai Institute of Coastal Zone Research, Chinese Academy of Sciences, 264003 Yantai, People's Republic of China

4 Key Laboratory of Soil Pollution Bioremediation of Zhejiang Province, Zhejiang A\&F University, 311300 Hangzhou, People’s Republic of China

5 University of Chinese Academy of Sciences, 100049 Beijing, People's Republic of China 
released into the environment (Ge et al. 2011; Gottschalk et al. 2009). $\mathrm{TiO}_{2}$ NPs enter the soil environment through intentional and unintentional releases, such as nanomaterial usage for environmental remediation, atmospheric deposition, industrial and domestic wastewater discharge, treatment and disposal of solid waste, and accidental spillage during manufacturing and transportation of nanoparticles (Ray et al. 2009; Menard et al. 2011). It has also been estimated that the environmental concentrations of $\mathrm{TiO}_{2} \mathrm{NPs}$ in sludge-treated soil may increase at rates as great as $42-89 \mu \mathrm{g} \mathrm{kg}^{-1} \mathrm{y}^{-1}$ (Gottschalk et al. 2009). With the further development of nanotechnology and the nanoindustry, it could be reasonably predicted that the concentration of $\mathrm{TiO}_{2} \mathrm{NPs}$ in soil will increase even further in the future (Fang et al. 2011).

Once released into the soil, $\mathrm{TiO}_{2} \mathrm{NPs}$ can adversely affect the metabolic activity of animals, plants, and microorganisms in the environment (Du et al. 2011; Ge et al. 2011; Menard et al. 2011; Ma et al. 2019). $\mathrm{TiO}_{2}$ NPs could also increase the transport and bioavailability of pollutants (Sun et al. 2007; Fang et al. 2011; Fang et al. 2013; Yang et al. 2014). The bioavailability and toxicity of nanoparticles released into the environment are strongly influenced by their stability and mobility behaviors (Zhang et al. 2015). A substantial number of studies have provided insights into the effects of environmental conditions, such as $\mathrm{pH}$, ionic strength, and valence state, and the presence of dissolved organic matter (DOM), clay minerals, and coexisting nanoparticles, on the stability and transport of $\mathrm{TiO}_{2} \mathrm{NPs}$. High concentrations of DOM and low ionic strength facilitated the transport of $\mathrm{TiO}_{2} \mathrm{NPs}$ in saturated porous media (Zhang et al. 2015), while iron oxides inhibited the mobility of $\mathrm{TiO}_{2}$ NPs in quartz columns (Han et al. 2014; Wang et al. 2016). However, natural soils, crucial environmental media, are complex assemblies of various components, and soil properties such as $\mathrm{pH}$, size, surface area, base saturation, mineral type, and organic matter composition can greatly affect the stability and mobility of nanoparticles (Kretzschmar et al. 1997; Sun et al. 2015c). The environmental behaviors of $\mathrm{TiO}_{2}$ NPs in soil may be different from those in simulated porous media (Sun et al. 2015a). Hence, it is urgent to explore the stability and transport of $\mathrm{TiO}_{2} \mathrm{NPs}$ in soil under the comprehensive effects of environmental conditions and to determine the critical factor affecting these behaviors. Some researchers have previously investigated the stability and mobility of engineered nanoparticles in soil. Fang et al. (2009) found that the stability of $\mathrm{TiO}_{2} \mathrm{NPs}$ in soil suspensions was positively correlated with the DOM concentration and clay content of the soils but was negatively correlated with ionic strength, $\mathrm{pH}$, and zeta potential; additionally, a significant portion of the $\mathrm{TiO}_{2}$ NPs (18.8-83.0\%) has readily passed through the soil columns containing soil particles of relatively larger diameters and lower solution ionic strengths, while $\mathrm{TiO}_{2} \mathrm{NPs}$ were significantly retained by soils with higher clay contents and salinity. Darlington et al. (2009) suggested that although many factors influenced the transport of aluminum nanoparticles, the size, charge, and agglomeration rate of the nanoparticles were predictive of their mobility in soils. However, transport of $\mathrm{TiO}_{2} \mathrm{NPs}$ in real soils is still inconclusive, and very few systematic studies have focused on the stability and transport of $\mathrm{TiO}_{2} \mathrm{NPs}$ in variable-charge soils with a high iron oxide content, commonly higher than $30 \mathrm{~g} \mathrm{~kg}^{-1}$ (Xu et al. 2003; Xu and Zhao 2013; Zhu et al. 2019). Variable-charge soils are widely distributed in economically developed regions and major grainproducing areas in southern China and are more likely to be a sink for intentionally or unintentionally released nanoparticles. Consequently, more attention should be paid to the stability and mobility behaviors in these soils.

The objective of this study was to investigate the stability of $\mathrm{TiO}_{2} \mathrm{NPs}$ in suspensions of three variable-charge soils and the transport of the nanoparticles in these soils and to determine the key factors controlling the stability and mobility of $\mathrm{TiO}_{2}$ NPs. The results of this work will hopefully provide insights into the environmental behaviors of $\mathrm{TiO}_{2} \mathrm{NPs}$ in variable-charge soils.

\section{Materials and methods}

\subsection{Soils}

Three surface $(0 \sim 15 \mathrm{~cm})$ variable-charge soils were collected from a section of dry land (YT-H) and a paddy field (YT-S) in Yingtan, Jiangxi Province, and a section of dry land (FY-H) in Fuyang, Zhejiang Province, China. The soils were air-dried, grounded, and passed through a 2-mm sieve prior to use. Soil $\mathrm{pH}$ was determined with a $\mathrm{pH}$ meter (FB10, Mettler Toledo) at a soil/deionized water $(18.2 \mathrm{M} \Omega \mathrm{cm})$ ratio of $1: 2.5\left(\mathrm{w} / \mathrm{v}^{-1}\right)$. Soil organic matter (SOM) was measured using potassium dichromate oxidation-ferrous sulfate titrimetry. The cation exchange capacity (CEC) of the soils was analyzed by the ammonium acetate method. The free iron oxide and aluminum oxide contents were measured by inductively coupled plasma optical emission spectroscopy (ICP-OES) (Pekin Elmer Optima 7000 DV) after extraction by sodium dithionite. The amorphous iron oxide and aluminum oxide contents were determined by ICPOES after being extracted by ammonium oxalate. All measurements above are referred to $\mathrm{Lu}$ (2000). Soil texture (sand, silt, and clay contents) parameters were measured using a laser particle analyzer (Malvern Mastersizer 2000F). The clay fraction $(<2 \mu \mathrm{m})$ separated from the soils by the sedimentation method was used for the determination of zeta potential of the soils with a Zetasizer Nano ZS 90 (Malvern).

\section{2 $\mathrm{TiO}_{2} \mathrm{NPs}$ and fulvic acid}

The $\mathrm{TiO}_{2}$ NPs used in this study were the same as those used in our previous work (Zhang et al. 2015). In brief, the 
nanoparticles were spherical with a nominal size of $30 \pm$ $10 \mathrm{~nm}$ and a specific surface area of $80.8 \mathrm{~m}^{2} \mathrm{~g}^{-1}$. The point of zero charge was determined to be at $\mathrm{pH} 6.2$ in deionized water by a Zetasizer Nano ZS 90. A stock suspension of $\mathrm{TiO}_{2}$ NPs was prepared by adding $250 \mathrm{mg} \mathrm{TiO}_{2} \mathrm{NPs}$ to $1.0-\mathrm{L}$ deionized water. The suspension was sonicated for $30 \mathrm{~min}(500$ $\mathrm{W}, 40 \mathrm{kHz})$ with vigorous stirring at room temperature $\left(25^{\circ} \mathrm{C}\right)$ and stored no longer than 2 days at $4{ }^{\circ} \mathrm{C}$. The fulvic acid (FA) obtained from the Fluka Regent Chemical Corporation was used as a model natural organic matter. Stock solutions of FA were prepared at $1 \mathrm{~g} \mathrm{~L}^{-1}$ in deionized water.

\subsection{Sedimentation of $\mathrm{TiO}_{2} \mathrm{NPs}$ in water leachate and suspensions of soils: batch experiments}

The soil suspensions in this study were obtained by mixing soils with deionized water at a ratio of $1: 20(\mathrm{w} / \mathrm{v})$ and equilibrating in a rotating shaker at $180 \mathrm{rpm}$ at $25^{\circ} \mathrm{C}$ for $24 \mathrm{~h}$. The suspensions were centrifuged at $3500 \times \mathrm{g}$ for $30 \mathrm{~min}$ and then filtered through a $0.45-\mu \mathrm{m}$ cellulose acetate filter membrane. The filtrates were referred to as soil leachates. The $\mathrm{pH}$ of the soil leachates was measured with a $\mathrm{pH}$ meter, and the electrical conductivity (EC) was determined using a conductivity meter (FE38, Mettler Toledo). The ionic strength (IS) of the soil suspensions was calculated using an empirical equation of IS and EC (Morrisson et al. 1990): IS $=0.0127 \times E C$, where IS and $\mathrm{EC}$ are in $\mathrm{mmol} \mathrm{L}^{-1}$ and $\mathrm{mS} \mathrm{cm}{ }^{-1}$, respectively. The DOM concentration in the soil suspensions was analyzed using a total organic carbon analyzer (Shimadzu TOV-VCPH).

The stability of $\mathrm{TiO}_{2} \mathrm{NPs}$ in soil leachates and suspensions was quantified by their sedimentation behaviors in this study. Ten milligrams of $\mathrm{TiO}_{2} \mathrm{NPs}_{\mathrm{s}}$ was added to soil leachates or soil suspensions to obtain a final $\mathrm{TiO}_{2} \mathrm{NPs}$ concentration of $50 \mathrm{mg}$ $\mathrm{L}^{-1}$. The mixtures were sonicated vigorously for $30 \mathrm{~min}(500$ $\mathrm{W}, 40 \mathrm{kHz}$ ), transferred into $250-\mathrm{mL}$ graduated cylinders, and allowed to settle undisturbed for $10 \mathrm{~h}$. Throughout the sedimentation process, aliquots of supernatant liquid $(1 \mathrm{~mL})$ were carefully periodically sampled from the top of the cylinders ( $2 \mathrm{~cm}$ below surface), and the concentration of $\mathrm{TiO}_{2} \mathrm{NPs}_{\mathrm{N}}$ was measured. The aggregate size distribution and zeta potential of $\mathrm{TiO}_{2}$ NPs in soil leachates were determined using a Zetasizer Nano ZS 90. After sedimentation, soil particles settled out and suspended in suspensions were analyzed on a scanning electron microscope (SEM, Hitachi S-4800 FE) equipped with an energy dispersive X-ray spectroscopy (EDS, Horiba EMAX7000) detector for examining the combination of these particles with $\mathrm{TiO}_{2}$ NPs.

Analysis of $\mathrm{TiO}_{2} \mathrm{NPs}$ concentrations in aqueous samples is referred to Zhang et al. (2007). Briefly, the $\mathrm{TiO}_{2}$ NPs suspension was first evaporated to dryness in glass tubes, followed by digestion with $5 \mathrm{~mL}$ of a sulfuric acid-ammonium sulfate solution by heating. The sulfuric acid-ammonium sulfate solution was prepared by mixing $400 \mathrm{~g}$ ammonium sulfate with
700-mL hot, concentrated sulfuric acid. Ti in digested samples was determined by ICP-OES, and the concentration of $\mathrm{TiO}_{2}$ NPs in the suspensions was calculated by the mass balance between $\mathrm{Ti}$ and $\mathrm{TiO}_{2}$.

\subsection{Transport of $\mathrm{TiO}_{2} \mathrm{NPs}$ in soils: column experiments}

Glass columns ( $2.5 \mathrm{~cm}$ in inner diameter and $10 \mathrm{~cm}$ in length) were packed uniformly with soils. The resulting porosity of the packed columns was gravimetrically measured to be $0.41-$ 0.44 (Table 2). Once packed, the column was flushed with 20 pore volumes (PVs) of deionized water, and the absorbance of the outflow at $420 \mathrm{~nm}$ was determined to be less than 0.006 , suggesting that the soil colloids in the outflow were negligible. Immediately prior to the next step, an aqueous suspension containing a final $\mathrm{TiO}_{2} \mathrm{NPs}$ concentration of $50 \mathrm{mg} \mathrm{L}^{-1}$ and a desired FA concentration of 0,5 , or $10 \mathrm{mg} \mathrm{L}^{-1}$ were produced by diluting the $\mathrm{TiO}_{2}$ NPs stock suspension and FA stock solution in deionized water. Subsequently, the prepared $\mathrm{TiO}_{2}$ NPs suspension was pumped into the columns, and the effluent was collected at regular time intervals using a BS-110A fraction collector (Huxi Analytical Instrument Factory Co., Ltd.). The concentration of $\mathrm{TiO}_{2} \mathrm{NPs}$ in influent $\left(\mathrm{C}_{0}\right)$ and effluent $(\mathrm{C})$ was determined by ICP-OES after digestion with sulfuric acid-ammonium sulfate. All solutions were introduced into columns upward by peristaltic pumps at a Darcy velocity of $0.39 \sim 0.44 \mathrm{~cm} \mathrm{~min}^{-1}$ for all experiments. All transport experiments were conducted in duplicate, and one representative breakthrough curve for each batch is shown in the results.

\section{Results and discussion}

\subsection{Characterization of soils}

The selected properties of the soils used in this study are summarized in Table 1. All three variable-charge soils are derived from quaternary red clay. The $\mathrm{pH}$ of the soil varied from 4.28 to 4.90 . The SOM content of YT-S was approximately three times as much as that of YT-H and FY-H. The free iron oxide content of YT-S was lower than that of YT-H and FY-H, but the amorphous iron oxide content was two and four times as much as that of YT-H and FY-H, respectively. Due to the anaerobic environment of paddy fields, a portion of crystalline iron oxide could be transformed to an amorphous state, and hence, the amorphous iron oxide content in paddy fields was generally higher than that in sections of dry land (Ma and Xu 2010). No significant distinction in texture was found among the three soils. According to Ley et al. (1994), the average soil particle diameters were the sum of the sand, silt, and clay particle diameters of $0.175,0.02$, and 0.0015 $\mathrm{mm}$, respectively, and multiplied by their respective 
Table 1 Physicochemical properties of the soils

\begin{tabular}{llll}
\hline & YT-H & YT-S & FY-H \\
\hline Sampling sites & Yingtan, Jiangxi & Yingtan, Jiangxi & Fuyang, Zhejiang \\
Agrotype & Humid ferralsols & Stagnic anthrosols & Humid ferralsols \\
Parent materials & Quaternary red clay & & \\
Land use types & Dry land & Paddy field & Rain-fed cropland \\
pH & 4.76 & 4.90 & 4.28 \\
SOM $(\%)^{1}$ & 1.12 & 3.86 & 1.18 \\
CEC $\left(\mathrm{cmol} \mathrm{kg}^{-1}\right)$ & 8.42 & 8.33 & 9.12 \\
Free iron oxide $\left(\mathrm{g} \mathrm{kg}^{-1}\right)$ & 44.1 & 20.5 & 48.2 \\
Free aluminum oxide $\left(\mathrm{g} \mathrm{kg}^{-1}\right)$ & 13.9 & 8.47 & 10.5 \\
Amorphous iron oxide $\left(\mathrm{g} \mathrm{kg}^{-1}\right)$ & 2.04 & 3.92 & 1.07 \\
Amorphous aluminum oxide $\left(\mathrm{g} \mathrm{kg}^{-1}\right)$ & 1.73 & 1.90 & 1.66 \\
Texture $(\%) \quad$ Clay & 22.5 & 20.4 & 21.4 \\
$\quad\left(<2 \mu \mathrm{m}^{2}\right)$ & & & 40.6 \\
$\quad$ Slit $(2-20 \mu \mathrm{m})$ & 42.9 & 43.7 & 38.0 \\
$\quad$ Sand $(20-2000 \mu \mathrm{m})$ & 34.6 & 35.9 & -15.6 \\
\hline Zeta potential $(\mathrm{mV})$ & -12.7 & -19.6 & \\
\hline
\end{tabular}

${ }^{1} \mathrm{SOM}(\%)$ refers to the dry weight of soils percentage contents in the soil. Consequently, the average particle diameters of YT-H, YT-S, and FY-H were 69, 72, and $75 \mu \mathrm{m}$, respectively.

\subsection{Stability of $\mathrm{TiO}_{2} \mathrm{NPs}$ in soil leachates and soil suspensions}

The essential physiochemical properties of soil leachates are shown in Tables 2 and 3. The $\mathrm{pH}$ varied from 4.89 to 5.50, slightly higher than that of the corresponding soil. The IS was lower than $0.5 \mathrm{mmol} \mathrm{L}^{-1}$. The DOM of YT-S was approximately twice that of the other two soils.

Take the ratio between the concentration of $\mathrm{TiO}_{2} \mathrm{NPs}$ suspended in soil leachates, $\mathrm{C}$, and the initial concentration of $\mathrm{TiO}_{2} \mathrm{NPs}, \mathrm{C}_{0}$, at specific time intervals as sedimentation behaviors index. Sedimentation curves of $\mathrm{TiO}_{2} \mathrm{NPs}$ in soil leachates are profiled in Fig. 1. The sedimentation of $\mathrm{TiO}_{2}$
NPs in soil leachates could be divided into two stages: a rapid settling period followed by a stable suspension period. After $3 \mathrm{~h}$ of rapid settling, $6.3 \% \pm 1.9 \%, 50 \% \pm 17 \%$, and $8.9 \% \pm$ $1.5 \%$ of the $\mathrm{TiO}_{2}$ NPs were still suspended in the YT-H, YT-S, and FY-H soil leachates, respectively. After $10 \mathrm{~h}$ of sedimentation, $38 \% \pm 0.4 \%$ of the $\mathrm{TiO}_{2}$ NPs still stably existed in the YT-S soil leachate, while the $\mathrm{TiO}_{2} \mathrm{NPs}$ in YT-H and FY-H soil leachates were less than $5 \%$. All these results above were in accordance with the size of $\mathrm{TiO}_{2} \mathrm{NPs}$ measured in soil leachates (Table 3). The aggregation size of $\mathrm{TiO}_{2} \mathrm{NPs}$ in the YT-H and FY-H soil leachates reached 583 and $574 \mathrm{~nm}$, respectively, larger than the $473 \mathrm{~nm}$ in the YT-S soil leachate. According to previous reports (Chowdhury et al. 2011; Shih et al. 2012; Zhang et al. 2015), an IS of soil leachate that was lower than $0.5 \mathrm{mmol} \mathrm{L}^{-1}$ had an ignorable effect on $\mathrm{TiO}_{2} \mathrm{NP}$ aggregation and sedimentation. Because of the higher $\mathrm{DOM}$ and $\mathrm{pH}$, the zeta potential of the $\mathrm{TiO}_{2}$ NPs was lower (the absolute value
Table 2 Physiochemical parameters of the soil columns

\begin{tabular}{llllllll}
\hline & Soil & $\begin{array}{l}\mathrm{TiO}_{2} \mathrm{NPs} \\
\left(\mathrm{mg} \mathrm{L}^{-1}\right)\end{array}$ & $\begin{array}{l}\mathrm{FA} \\
\left(\mathrm{mg} \mathrm{L}^{-1}\right)\end{array}$ & $\begin{array}{l}\text { Average particle } \\
\text { size of soil }(\mu \mathrm{m})\end{array}$ & Porosity & $\begin{array}{l}\text { Flow velocity } \\
\left(\mathrm{cm} \mathrm{min}^{-1}\right)\end{array}$ & Elution rate \\
\hline EX-01 & YT-H & 50 & 0 & 69 & 0.41 & 0.44 & 0 \\
EX-02 & & & 5 & & 0.42 & 0.40 & 0.003 \\
EX-03 & & & 10 & & 0.41 & 0.39 & 0.208 \\
EX-04 & YT-S & 50 & 0 & 72 & 0.44 & 0.40 & 0 \\
EX-05 & & & 5 & & 0.43 & 0.39 & 0 \\
EX-06 & & & 10 & & 0.43 & 0.41 & 0 \\
EX-07 & FY-H & 50 & 0 & 75 & 0.41 & 0.41 & 0.025 \\
EX-08 & & & 5 & & 0.43 & 0.43 & 0.159 \\
EX-09 & & & 10 & & 0.42 & 0.40 & 0.378 \\
\hline
\end{tabular}


was greater, Table 3); therefore, the $\mathrm{TiO}_{2} \mathrm{NPs}$ were more stable in the YT-S soil leachate.

Except for the properties identical to those of soil leachates, such as ion and DOM contents, the soil particles in soil suspensions should interact with $\mathrm{TiO}_{2} \mathrm{NPs}$ and affect their stabilization (Fang et al. 2009; Sun et al. 2015b). Sedimentation curves of $\mathrm{TiO}_{2}$ NPs in soil suspensions are presented in Fig. 2. Similar to the settling behaviors in soil leachates, $\mathrm{TiO}_{2} \mathrm{NPs}$ were more stable in the YT-S soil suspension. However, the sedimentation of the $\mathrm{TiO}_{2} \mathrm{NPs}$ was rapid, being completed in $1 \mathrm{~h}$. One hour later, $43 \% \pm 3.1 \%$ of $\mathrm{TiO}_{2} \mathrm{NPs}$ existed stably in the YT-S soil suspension, while over $99 \%$ of $\mathrm{TiO}_{2} \mathrm{NPs}_{\mathrm{N}}$ in the YT-H and FY-H soil suspensions had already settled out. After $10 \mathrm{~h}$ of sedimentation, $27 \% \pm 4.4 \%$ of $\mathrm{TiO}_{2} \mathrm{NPs}$ remained stable in the YT-S soil suspension. Fang et al. (2009) found that the $\mathrm{TiO}_{2} \mathrm{NPs}$ in suspension after $24 \mathrm{~h}$ were positively correlated with the DOM and clay contents of the soils but negatively correlated with the ionic strength, $\mathrm{pH}$, and zeta potential. After settling for $24 \mathrm{~h}, 31.1-35.8 \%$ of the $\mathrm{TiO}_{2}$ NPs particles were suspended in soil suspensions with a higher DOM content and lower IS, while more than $98 \%$ of the initial $\mathrm{TiO}_{2}$ NPs had been deposited in soil suspensions with a higher IS and lower DOM content. There was almost no significant difference in the clay contents among the three soils in this study, and therefore, the clay content was not the main reason for the distinct settling behaviors of $\mathrm{TiO}_{2} \mathrm{NPs}$. The lower zeta potential of $\mathrm{TiO}_{2}$ NPs in the YT-S soil suspension was reasonably attributed to the higher DOM content derived from the higher SOM. Hence, the higher SOM of YT-S stabilized $\mathrm{TiO}_{2}$ NPs in the soil suspension.

During sedimentation, the $\mathrm{Fe}$ and $\mathrm{Al}$ contents of the suspended mixture were also measured with ICP-OES after digestion with $\mathrm{HF}-\mathrm{HNO}_{3}-\mathrm{HClO}_{4}$ to represent the settling behaviors of soil particles. As demonstrated in Fig. 3, the deposition of soil particles coincided with that of $\mathrm{TiO}_{2} \mathrm{NPs}$. According to the results of a Pearson correlation analysis (SPSS version 20.0), there was a significant positive correlation between suspended $\mathrm{TiO}_{2} \mathrm{NPs}$ and the contents of $\mathrm{Fe}(r=$ $0.984, p<0.01)$ and $\mathrm{Al}(r=0.993, p<0.01)$ in the suspension, which indicated the cosedimentation of $\mathrm{TiO}_{2} \mathrm{NPs}$ and soil particles. SEM-EDS analysis of small suspended soil particles and large deposited soil particles demonstrated that the surface of both small and large soil particles adsorbed $\mathrm{TiO}_{2} \mathrm{NPs}$

Table 3 Properties of the soil leachates

\begin{tabular}{llllll}
\hline & $\mathrm{pH}$ & $\begin{array}{l}\mathrm{IS} \\
\left(\mathrm{mmol} \mathrm{L}^{-1}\right)\end{array}$ & $\left.\begin{array}{l}\mathrm{DOM} \\
(\mathrm{mgC} \mathrm{L}-\end{array}{ }^{1}\right)$ & $\begin{array}{l}\text { Zeta potential }^{1} \\
(\mathrm{mV})\end{array}$ & $\begin{array}{l}\text { Particle size }^{1} \\
(\mathrm{~nm})\end{array}$ \\
\hline YT-H & 5.22 & 0.45 & 22.6 & -25.3 & 583 \\
YT-S & 5.50 & 0.40 & 43.1 & -30.2 & 471 \\
FY-H & 4.89 & 0.36 & 23.7 & -24.5 & 574 \\
\hline
\end{tabular}

${ }^{1}$ Zeta potential and particle size of $\mathrm{TiO}_{2} \mathrm{NPs}$ in soil leachate

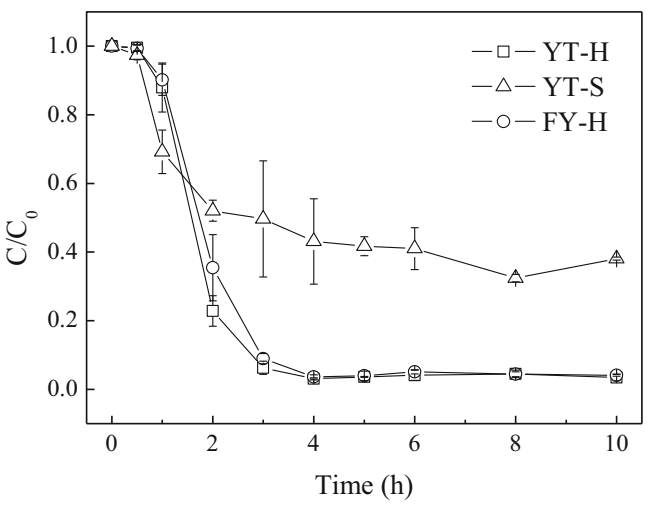

Fig. 1 Sedimentation curves of $\mathrm{TiO}_{2} \mathrm{NPs}$ in the soil leachates

aggregates (Fig. 4), which confirmed the cosedimentation of $\mathrm{TiO}_{2}$ NPs and soil particles. The positively charged iron and aluminum oxides on the surface of soil particles could electrostatically adsorb the negatively charged $\mathrm{TiO}_{2} \mathrm{NPs}$. In addition, the roughness of the soil particle surface promoted the capture of $\mathrm{TiO}_{2}$ NPs (Sun et al. 2015b).

\subsection{Transport of $\mathrm{TiO}_{2} \mathrm{NPs}$ in soil columns}

In column experiments, breakthrough curves of $\mathrm{TiO}_{2} \mathrm{NPs}$ in soils were plotted as dimensionless concentrations $\left(\mathrm{C} / \mathrm{C}_{0}\right)$ of $\mathrm{TiO}_{2} \mathrm{NPs}$ vs. PVs, as illustrated in Fig. 5. In the absence of FA, no $\mathrm{TiO}_{2}$ NPs could be eluted from the YT-H and YT-S soil columns; $\mathrm{TiO}_{2}$ NPs could be flushed from the FY-H soil column $\left(\mathrm{C} / \mathrm{C}_{0}>0.01\right)$, but $\mathrm{C} / \mathrm{C}_{0}$ was merely 0.11 at $100 \mathrm{PVs}$; moreover, the elution rate of $\mathrm{TiO}_{2} \mathrm{NPs}$ was 0.025 throughout the transport experiment (Table 2). Previous studies also found that the mobility of nanoparticles in soils was weak. $\mathrm{TiO}_{2} \mathrm{NPs}$ were significantly retained in soils with higher clay contents and salinity and lower DOM contents (Fang et al. 2009). Zhao et al. (2012a, b) demonstrated that 93-99\% of $\mathrm{ZnO}$ nanoparticles were retained in sandy loam soil. Wang et al. (2014) investigated the mobility of water-dispersed engineered nanoparticles in a red soil (Ultisol) and found that more than $90 \%$ of

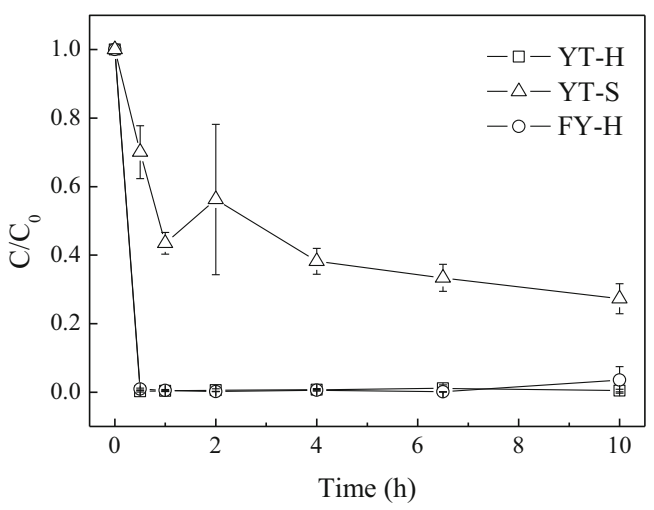

Fig. 2 Sedimentation curves of $\mathrm{TiO}_{2} \mathrm{NPs}$ in the soil suspensions 

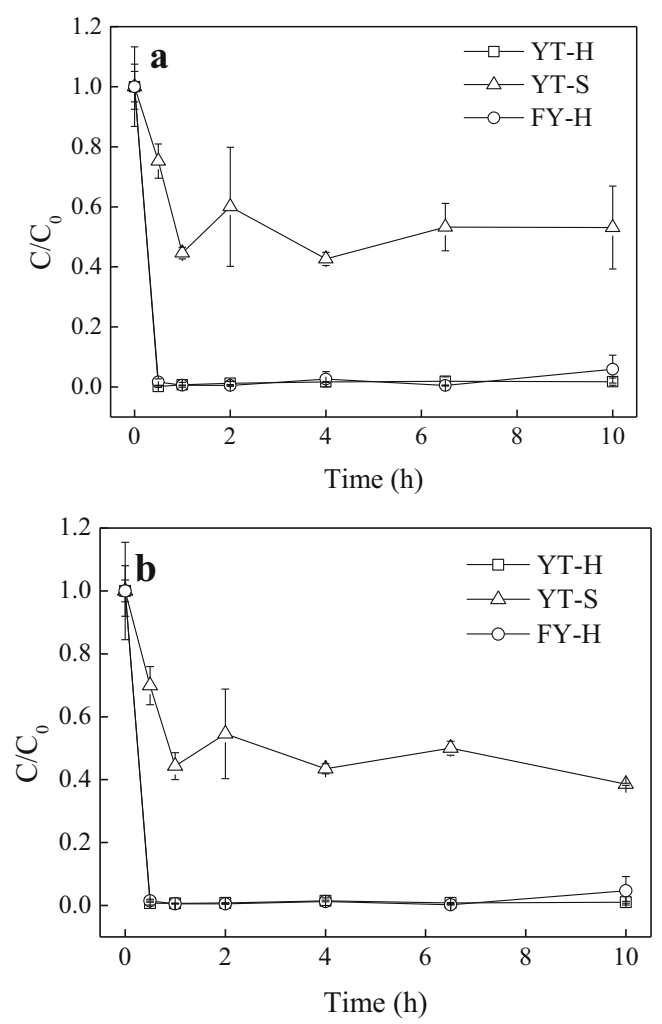

Fig. 3 Relative concentrations of $\mathrm{Fe}$ (a) and $\mathrm{Al}$ (b) in the soil suspensions during sedimentation

$\mathrm{TiO}_{2}$ NPs, Ag nanoparticles, buckminsterfullerenes, and single-walled carbon nanotubes could not pass through the soil columns.
Generally, it is the physical filtration and physicochemical interactions between nanoparticles and soil particles that mainly contribute to the retention of nanoparticles in soils (Jaisi et al. 2008; Darlington et al. 2009; Fang et al. 2009). Straining is the trapping of the particles in the downgradient mobile-water conduits that are too narrow to allow particles to pass (Mcdowellboyer et al. 1986). In principle, straining is governed by the size of the particles and the pore size distribution of the porous media (Zhang et al. 2015). Empirically, particles were retained if their diameter exceeded $0.2-5 \%$ of the diameter of the porous media grains (Redman et al. 2004; Jaisi et al. 2008). However, straining has also been considered to be an important particle retention mechanism when the ratio of the particle diameter to the media grain diameter is larger than 0.0017 (Bradford et al. 2002; Chen et al. 2012), and straining could even be more important if the collector grains were rough and irregular in shape (Bradford et al. 2002; Tufenkji and Elimelech 2004). In this study, the aggregate size of $\mathrm{TiO}_{2} \mathrm{NPs}$ in deionized water without FA was up to $498 \mathrm{~nm}$, which was $0.66-0.72 \%$ of the mean size of the three soil particles. Therefore, it could be reasonably inferred that straining was inevitably involved in the retention of $\mathrm{TiO}_{2}$ NPs in the soils. In addition, the straining potential of the porous soil media was significantly increased due to the high heterogeneity and shape irregularity of the soils.

$\mathrm{TiO}_{2}$ NPs with a zeta potential of $-18.2 \mathrm{mV}$ in deionized water and in the absence of FA were prone to be adsorbed onto the positively charged surface of soil particles, which was another crucial reason for the significant retention of $\mathrm{TiO}_{2}$
Fig. 4 SEM-EDS of YT-S soil particles deposited $(\mathrm{a}, \mathrm{b})$ and suspended (c, d)
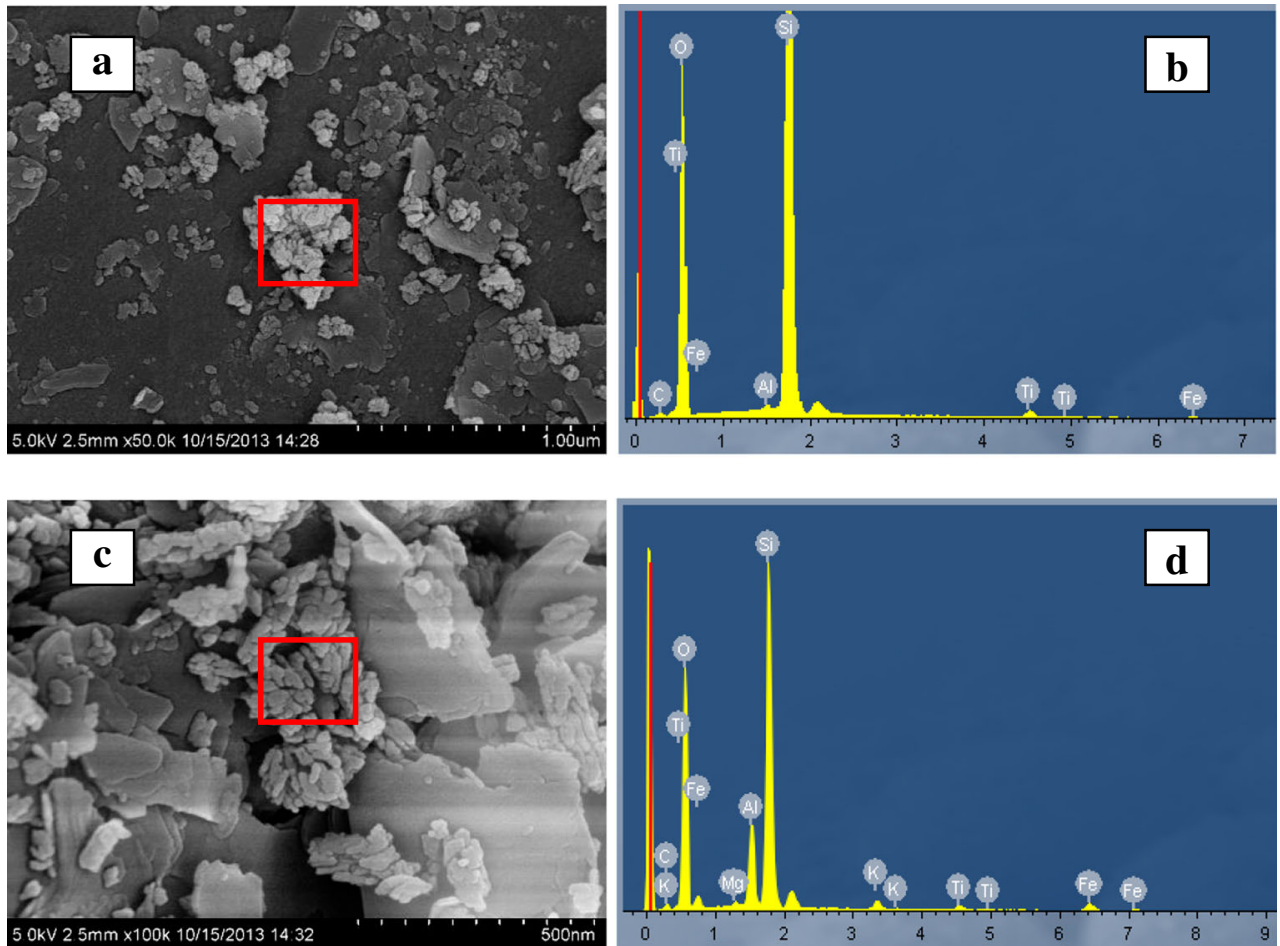

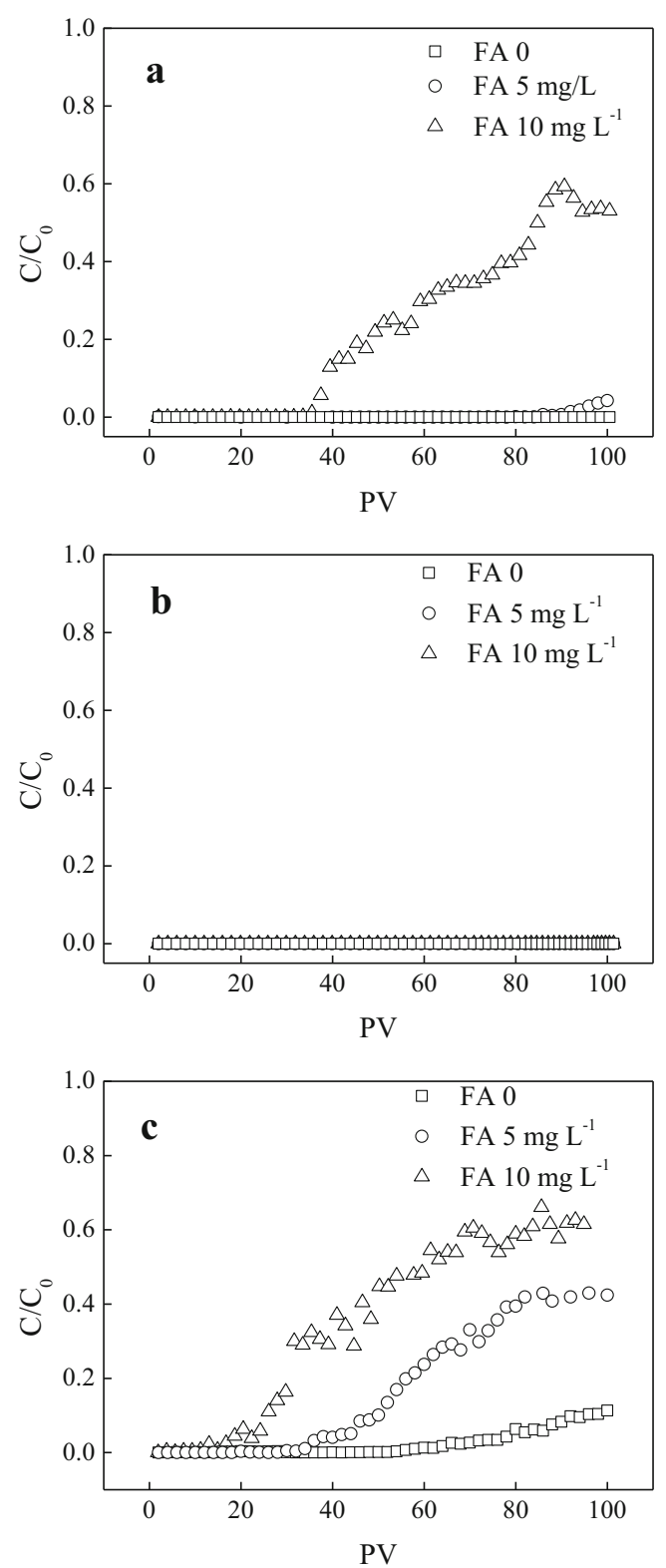

Fig. 5 Breakthrough curves of $\mathrm{TiO}_{2}$ NPs in YT-H (a), YT-S (b), and FY$\mathrm{H}$ (c) soil columns

NPs in the soils. Zhao et al. (2012a, b) suggested that although $\mathrm{ZnO}$ nanoparticles exhibited low mobility in a sandy loam soil, soil colloids might act as carriers of strongly adsorbed nanoparticles and enhance their passage away from the soil. Another investigation also found that kaolin and bentonite increased the transport of $\mathrm{TiO}_{2} \mathrm{NPs}$ in porous quartz sand in the presence of $\mathrm{NaCl}$ (Cai et al. 2014). However, although a portion of $\mathrm{TiO}_{2} \mathrm{NPs}_{\text {adsorbed onto the surface of soil particles }}$ suspended stably in the YT-S soil suspension, the absorbed $\mathrm{TiO}_{2} \mathrm{NPs}$ were finally retained in soils, resulting from the lack of soil particle migration throughout the transport experiments. Thus, the mobility of $\mathrm{TiO}_{2} \mathrm{NPs}$ in soils was not directly related to their stability in soil suspensions in this study. Wang et al. (2018) suggested that the retention capacity of $\mathrm{Ag}$ nanoparticles in soils was positively correlated with the iron oxide content. Generally, the specific area of amorphous iron oxide is larger than that of free iron oxide, and it was reasonably concluded that the positively charged amorphous iron oxide could exert stronger inhibition of the transport of the negatively charged $\mathrm{TiO}_{2} \mathrm{NPs}$ than free iron oxide due to the greater adsorption of nanoparticles. Unlike the complete retention in YT-H and YT-S soils, a small amount of $\mathrm{TiO}_{2} \mathrm{NPs}$ could be eluted from the FY-H soil column because of the lower adsorption by the lower amorphous iron oxide content. It was suggested that the difference in the amorphous iron oxide content influenced the disparity in the transport behaviors of $\mathrm{TiO}_{2} \mathrm{NPs}$ in the three variable-charge soils. Despite the high content of SOM, no mobility of $\mathrm{TiO}_{2} \mathrm{NPs}$ was observed in YT-H soil, which indicated that SOM was not a key factor affecting the migration of $\mathrm{TiO}_{2} \mathrm{NPs}$ in soils in this study.

In general, except for the physicochemical properties of soil, the transport and retention behaviors of nanoparticles were remarkably affected by their characteristics (Jaisi et al. 2008; Fang et al. 2009). Nanoparticles modified by organic matter or surfactants exhibited high mobility in soils or wellcontrolled porous quartz sand. Compared to pristine nanoparticles, the maximum relative concentration $\left(\mathrm{C} / \mathrm{C}_{0}\right)$ of $\mathrm{ZnO}$ nanoparticles modified with sodium citrate increased elution from sandy soils and sandy loam soils by 0.04 and 0.02 , respectively (Zhao et al. 2012a). DOM coating facilitated the transport of nanoparticles in saturated porous quartz- and iron oxide-coated quartz sand (Han et al. 2014; Zhang et al. 2015). As shown in Fig. 5, FA enhanced the mobility of $\mathrm{TiO}_{2} \mathrm{NPs}_{\text {in }}$ YT-H and FY-H soils. In the YT-H assay, the elution rate of $\mathrm{TiO}_{2}$ NPs dispersed by $5 \mathrm{mg} \mathrm{L}-1$ of FA was $0.3 \%$, and it increased to $20.8 \%$ when increasing the FA concentration to $10 \mathrm{mg} \mathrm{L}^{-1}$. Meanwhile, the breakthrough time (the PVs when $\mathrm{C} / \mathrm{C}_{0}>0.01$ ) shifted earlier from $90 \mathrm{PVs}$ to $36 \mathrm{PVs}$. Likewise, FA induced the increase in elution and the advance of the breakthrough time of $\mathrm{TiO}_{2} \mathrm{NPs}$ in FY-H soil columns. The promotion of the $\mathrm{TiO}_{2}$ NPs mobility in soil columns by FA could be summarized as follows: (1) FA dispersed $\mathrm{TiO}_{2} \mathrm{NPs}$, and nanoparticles of smaller size tended to exhibit higher mobility ( Guzman et al. 2006; Solovitch et al. 2010; Chinnapongse et al. 2011; Rottman et al. 2013). The aggregate size of $\mathrm{TiO}_{2}$ NPs dispersed in $10 \mathrm{mg} \mathrm{L}^{-1}$ FA was $448 \mathrm{~nm}$, smaller than that in $5 \mathrm{mg} \mathrm{L}^{-1} \mathrm{FA}(505 \mathrm{~nm})$ and in deionized water $(529 \mathrm{~nm})$. (2) Unbonded FA in suspension could be adsorbed onto the surface of soil particles neutralizing the positive charge of the grain, occupying the available adsorption sites, and, therefore, diminishing the adsorption of $\mathrm{TiO}_{2}$ NPs onto the soil particles. The lack of DOM determined in the outflow after removal of $\mathrm{TiO}_{2} \mathrm{NPs}_{\mathrm{N}}$ suggested the complete adsorption of free FA by the soil particles in columns. Unlike the mobility in YT-H and FY-H soils, no FA-dispersed $\mathrm{TiO}_{2}$ NPs could be flushed from YT-S soil columns, which further confirmed that a higher content of amorphous iron oxide was 
the major factor accounting for the total retention of $\mathrm{TiO}_{2} \mathrm{NPS}$ in YT-S.

\section{Conclusions}

The stability and transport behaviors of $\mathrm{TiO}_{2}$ NPs in three variable-charge soil samples were studied in batch and column experiments. The stability of $\mathrm{TiO}_{2} \mathrm{NPs}$ in soil suspensions was strongly associated with the SOM of the tested soils, and better stability of $\mathrm{TiO}_{2}$ NPs was observed in the YT-S suspension, with a higher SOM content. However, the transport of $\mathrm{TiO}_{2}$ NPs in soils was not directly related to their stability in soil suspensions. The difference in the positively charged amorphous iron oxide content induced the disparity in the mobility of $\mathrm{TiO}_{2}$ NPs in the tested soils. A small amount of $\mathrm{TiO}_{2}$ NPs was eluted from FY-H, with a low amorphous iron oxide content, while all $\mathrm{TiO}_{2}$ NPs were retained in YT-H and YT-S. Moreover, FA facilitated $\mathrm{TiO}_{2}$ NPs transport in soils by dispersing $\mathrm{TiO}_{2}$ NPs and reducing the adsorption of $\mathrm{TiO}_{2} \mathrm{NPs}$ onto soil particles.

Acknowledgements This work was supported by the National Natural Science Foundation of China (41601520, 41230858, and 41171248). The authors also gratefully acknowledge the editor and anonymous reviewers for their valuable comments and helpful suggestions to the manuscript.

\section{Compliance with ethical standards}

Conflict of interest The authors declare that they have no conflict of interest.

\section{References}

Bradford SA, Yates SR, Bettahar M, Simunek J (2002) Physical factors affecting the transport and fate of colloids in saturated porous media. Water Resour Res 38:63-1-63-12

Cai L, Tong MP, Wang XT, Kim H (2014) Influence of clay particles on the transport and retention of titanium dioxide nanoparticles in quartz sand. Environ Sci Technol 48:7323-7332

Chen GX, Liu XY, Su CM (2012) Distinct effects of humic acid on transport and retention of $\mathrm{TiO}_{2}$ rutile nanoparticles in saturated sand columns. Environ Sci Technol 46:7142-7150

Chinnapongse SL, MacCuspie RI, Hackley VA (2011) Persistence of singly dispersed silver nanoparticles in natural freshwaters, synthetic seawater, and simulated estuarine waters. Sci Total Environ 409: 2443-2450

Chowdhury I, Hong Y, Honda RJ, Walker SL (2011) Mechanisms of $\mathrm{TiO}_{2}$ nanoparticle transport in porous media: role of solution chemistry, nanoparticle concentration, and flowrate. J Colloid Interf Sci 360:548-555

Darlington TK, Neigh AM, Spencer MT, Nguyen OT, Oldenburg SJ (2009) Nanoparticle characteristics affecting environmental fate and transport through soil. Environ Toxicol Chem 28:1191-1199

Du WC, Sun YY, Ji R, Zhu JG, Wu JC, Guo HY (2011) $\mathrm{TiO}_{2}$ and $\mathrm{ZnO}$ nanoparticles negatively affect wheat growth and soil enzyme activities in agricultural soil. J Environ Monitor 13:822-828
Fang J, Shan XQ, Wen B, Lin JM, Owens G (2009) Stability of titania nanoparticles in soil suspensions and transport in saturated homogeneous soil columns. Environ Pollut 157:1101-1109

Fang J, Shan XQ, Wen B, Lin JM, Owens G, Zhou SR (2011) Transport of copper as affected by titania nanoparticles in soil columns. Environ Pollut 159:1248-1256

Fang J, Xu MJ, Wang DJ, Wen B, Han JY (2013) Modeling the transport of $\mathrm{TiO}_{2}$ nanoparticle aggregates in saturated and unsaturated granular media: effects of ionic strength and $\mathrm{pH}$. Water Res 47:1399-1408

Ge YG, Schimel JP, Holden PA (2011) Evidence for negative effects of $\mathrm{TiO}_{2}$ and $\mathrm{ZnO}$ nanoparticles on soil bacterial communities. Environ Sci Technol 45:1659-1664

Gottschalk F, Sonderer T, Scholz RW, Nowack B (2009) Modeled environmental concentrations of engineered nanomaterials $\left(\mathrm{TiO}_{2}, \mathrm{ZnO}\right.$, $\mathrm{Ag}, \mathrm{CNT}$, fullerenes) for different regions. Environ Sci Technol 43: 9216-9222

Guzman KD, Finnegan M, Banfield J (2006) Influence of surface potential on aggregation and transport of titania nanoparticles. Environ Sci Technol 40:7688-7693

Han P, Wang XT, Cai L, Tong MP, Kim H (2014) Transport and retention behaviors of titanium dioxide nanoparticles in iron oxide-coated quartz sand: effects of $\mathrm{pH}$, ionic strength, and humic acid. Colloid Surface A 454:119-127

Jaisi DP, Saleh NB, Blake RE, Elimelech M (2008) Transport of singlewalled carbon nanotubes in porous media: filtration mechanisms and reversibility. Environ Sci Technol 42:8317-8323

Kretzschmar R, Barmettler K, Grolimund D, Yan YD, Borkovec M, Sticher H (1997) Experimental determination of colloid deposition rates and collision efficiencies in natural porous media. Water Resour Res 33:1129-1137

Ley TW, Stevens RG, Topielec RR, Neibling WH (1994) Soil water monitoring and measurement. Pacific Northwest Publication, Washington

Lu RK (2000) Analytical Method of Soil Agro chemistry. Chinese Agriculture Science and Technology Press, Beijing

Ma L, Xu R (2010) Physico-chemical characteristics of paddy soils derived from quaternary red clay under different cultivated years. Soils 42:560-563

Ma HB, Lenz KA, Gao XF, Li SB, Wallis LK (2019) Comparative toxicity of a food additive $\mathrm{TiO}_{2}$, a bulk $\mathrm{TiO}_{2}$, and a nano-sized P25 to a model organism the nematode $C$. elegans. Environ Sci Pollut Res 26:3556-3568

Mcdowellboyer LM, Hunt JR, Sitar N (1986) Particle-transport through porous-media. Water Resour Res 22:1901-1921

Menard A, Drobne D, Jemec A (2011) Ecotoxicity of nanosized $\mathrm{TiO}_{2}$ Review of in vivo data. Environ Pollut 159:677-684

Morrisson AR, Park JS, Sharp BL (1990) Application of highperformance size-exclusion liquid-chromatography to the study of copper speciation in waters extracted from sewage-sludge treated soils. Analyst 115:1429-1433

Ray PC, Yu HT, Fu PP (2009) Toxicity and environmental risks of nanomaterials: challenges and future needs. J Environ Sci Heal C 27:1-35

Redman JA, Walker SL, Elimelech M (2004) Bacterial adhesion and transport in porous media: role of the secondary energy minimum. Environ Sci Technol 38:1777-1785

Rottman J, Platt LC, Sierra-Alvarez R, Shadman F (2013) Removal of $\mathrm{TiO}_{2}$ nanoparticles by porous media: effect of filtration media and water chemistry. Chem Eng J 217:212-220

Shih YH, Liu WS, Su YF (2012) Aggregation of stabilized $\mathrm{TiO}_{2}$ nanoparticle suspensions in the presence of inorganic ions. Environ Toxicol Chem 31:1693-1698

Solovitch N, Labille J, Rose J, Chaurand P, Borschneck D, Wiesner MR, Bottero JY (2010) Concurrent aggregation and deposition of $\mathrm{TiO}_{2}$ nanoparticles in a sandy porous media. Environ Sci Technol 44: 4897-4902 
Sun HW, Zhang XZ, Niu Q, Chen YS, Crittenden JC (2007) Enhanced accumulation of arsenate in carp in the presence of titanium dioxide nanoparticles. Water Air Soil Poll 178:245-254

Sun PD, Shijirbaatar A, Fang J, Owens G, Lin DH, Zhang K (2015a) Distinguishable transport behavior of zinc oxide nanoparticles in silica sand and soil columns. Sci Total Environ 505:189-198

Sun PD, Zhang KK, Fang J, Jin G (2015b) Experimental study on the effecting mechanisms of soil particles on the stability of $\mathrm{TiO}_{2}$ nanoparticles. Acta Scientiae Circumstantiae 35:844-854

Sun PD, Zhang KK, Fang J, Lin DH, Wang MH, Han JY (2015c) Transport of $\mathrm{TiO}_{2}$ nanoparticles in soil in the presence of surfactants. Sci Total Environ 527:420-428

Tufenkji N, Elimelech M (2004) Correlation equation for predicting single-collector efficiency in physicochemical filtration in saturated porous media. Environ Sci Technol 38:529-536

Wang DJ, Su CM, Zhang W, Hao XZ, Cang L, Wang YJ, Zhou DM (2014) Laboratory assessment of the mobility of water-dispersed engineered nanoparticles in a red soil (Ultisol). J Hydrol 519: $1677-1687$

Wang M, Gao B, Tang DS (2016) Review of key factors controlling engineered nanoparticle transport in porous media. J Hazard Mater 318:233-246

Wang R, Du H, Wang YJ, Wang DJ, Sun Q, Zhou DM (2018) Retention of silver nanoparticles and silver ion to natural soils: effects of soil physicochemical properties. J Soils Sediments 18:2491-2499

Xu RK, Zhao AZ (2013) Effect of biochars on adsorption of Cu(II), Pb(II) and $\mathrm{Cd}(\mathrm{II})$ by three variable charge soils from southern China. Environ Sci Pollut Res 20:8491-8501

Xu RK, Zhao AZ, Ji GL (2003) Effect of low-molecular-weight organic anions on surface charge of variable charge soils. J Colloid Interf Sci 264:322-326
Yang WW, Wang Y, Huang B, Wang NX, Wei ZB, Luo J, Miao AJ, Yang $\mathrm{LY}$ (2014) $\mathrm{TiO}_{2}$ nanoparticles act as a carrier of Cd bioaccumulation in the ciliate Tetrahymena thermophila. Environ Sci Technol 48: 7568-7575

Zhang XZ, Sun HW, Zhang ZY, Niu Q, Chen YS, Crittenden JC (2007) Enhanced bioaccumulation of cadmium in carp in the presence of titanium dioxide nanoparticles. Chemosphere 67:160-166

Zhang RC, Zhang HB, Tu C, Hu XF, Li LZ, Luo YM, Christie P (2015) Facilitated transport of titanium dioxide nanoparticles by humic substances in saturated porous media under acidic conditions. J Nanopart Res 17:165

Zhao LJ, Peralta-Videa JR, Hernandez-Viezcas JA, Hong J, GardeaTorresdey JL (2012a) Transport and retention behavior of $\mathrm{ZnO}$ nanoparticles in two natural soils: effect of surface coating and soil composition. J Nano Res 17:229-242

Zhao LJ, Peralta-Videa JR, Ren MH, Varela-Ramirez A, Li CQ, Hernandez-Viezcas JA, Aguilera RJ, Gardea-Torresdey JL (2012b) Transport of $\mathrm{Zn}$ in a sandy loam soil treated with ZnO NPs and uptake by corn plants: electron microprobe and confocal microscopy studies. Chem Eng J 184:1-8

Zhu M, Hu XF, Tu C, Luo YM, Yang RY, Zhou SB, Cheng NN, Roylott (2019) Speciation and sorption structure of diphenylarsinic acid in soil clay mineral fractions using sequential extraction and EXAFS spectroscopy. J Soils Sediments.:1-12. https://doi.org/10.1007/ s11368-019-02431-2

Publisher's note Springer Nature remains neutral with regard to jurisdictional claims in published maps and institutional affiliations. 